\author{
로봇활용수업에서 교사의 수업언어 사용 유형 분석 \\ 김두규 $\cdot$ 김경현 $^{+}$ \\ (부산대학교 - ${ }^{\dagger}$ 원광대학교)
}

\title{
Analyze Teacher's Lesson Language Pattern Based on Lesson of Using Robot
}

\author{
Du-Guy KIM • Gyung-Hyun $\mathrm{KIM}^{+}$ \\ (Pusan National University $\cdot{ }^{\dagger}$ Wonkwang University)
}

\begin{abstract}
The purpose of this research is to analyze teacher's lesson language pattern based on robot class. For this research as an analytical tool AF (Advanced Flanders) was utilized. Actually ClassReport ver 1.0 computer program was used in the process of input data. From the results of the Flanders index, The major instruction sequences were 4-8-3 in elementary school and 4-8 in middle school. The teacher's remarks in robot class in the elementary school rank 'instruction', 'question'. And In the middle school rank 'instruction' and 'positive advice' are very high ratio, but 'indication' is low ratio. The teacher constantly teach and ask question ratio in the middle school was higher than elementary school. But a tendency for non-indication was low ratio in the middle school than elementary school. These results could provide effective cues and information on how to to improve instruction.
\end{abstract}

Key words : Analyze lesson language pattern, Flanders, Robot lesson

\section{I. 서 론}

‘배움의 과정이 즐거우면서도 학습 효과가 탁 월한 교육 방법은 무엇일까?'에 대한 의문은 동 서고금을 막론하고 교육 현장에서 꾸준히 제기되 고 있다. 최근 이러한 물음에 대한 대안적인 사 례로 구성주의 철학에 기초한 협동학습에 대한 관심이 높아지고 있다.

그러나 막상 교사가 학생들에게 '즐거우면서도 학습 효과가 탁월한 협동적인 문제 공간을 제공 하는 일은 여간 어려운 과업이 아니다. 여기서
효과적인 테크놀러지의 활용은 이러한 교사의 수 고를 현저히 덜어줄 수 있다. 테크놀러지를 수업 에 효과적으로 활용하면 교사들은 우선 자신의 수업을 보다 유연하고 흥미롭게 만들 수 있으며, 여기에 테크놀러지 간의 결합이 더해지면 최적의 학습경험을 계획하고 조성하는 데 도움이 되기 때문이다(Culp \& Mandinach, 2004).

수업에 활용 가능한 차세대 테크놀러지(증강현 실, 디지털교과서, 모바일, IPTV, 스마트기기, 로 봇 등) 중에서 로봇매체는 구성주의에 기초한 협 동학습을 실천하는 데 있어서 상당히 추천할만한

† Corresponding author : 010-2834-8858, edukim@wku.ac.kr 
매체로서의 가치를 지닌다. 특히 2011년에 초·중. 고등학교의 정규 교육과정에 시범적으로 도입한 로봇활용수업은 교육매체로서의 로봇의 교육적 가능성을 탐색해 본다는 점과 교육매체의 새로운 지평을 확장한다는 점에서 매우 의미있는 교육적 시도라고 할만하다.

효과적인 수업을 논하는 데 있어 교사가 어떤 형태의 수업언어를 사용했는지 혹은 어떤 경향의 수업언어를 사용했는지는 늘 중요한 요인으로 대 두되었다. 왜냐하면 교사는 수업 중 대다수의 시 간을 언어로써 학생과 상호작용하여 의도적인 메 시지를 전달하며, 이 과정에서 사용한 교사의 수 업언어의 양과 질은 학생의 학업성취와 직결되기 때문이다.

교육용 로봇과 관련한 선행 연구들(권순범 외, 2011; 김미량 외, 2008; 김영실 외, 2011; 박응식 외, 2009; 박정호 외, 2011; 송정범 외, 2011; 신나 민 외, 2007; 유구종 외, 2011; 이경희, 2010; 이영 준 외, 2007; 한정혜 외, 2006)은 로봇교육을 위한 프로그램 개발 및 운영방안, 로봇의 교육적 기능 연구, 교육을 위한 로봇 디자인 그리고 로봇을 매개로 한 사고력 계발의 네가지 영역 등이 주류 를 이루었다. 반면, 정규교육과정으로 편성된 과 목을 지도하는 데 있어서 발생되는 교육적 효과 에 대한 연구는 부족하였으며, 특히 교사의 수업 전문성의 대표적인 영역인 수업언어를 어떻게 사 용하였는지 등에 대한 연구는 부족하였다.

따라서, 본 연구에서는 로봇활용수업의 효과성 을 검증하기 위해서는 로봇이 실제로 교사의 수 업전문성의 대표적인 영역인 수업언어를 어떻게 개선하는지에 대한 구체적인 데이터를 수집하고 이를 분석함으로써 교사가 어떤 유형과 수준의 질문을 했는지, 학생의 발언은 어떤 경향을 보였 는지, 언어 상호작용이 없을 경우에 어떤 수업 상황이 발생했는지에 대한 구체적이고도 세부적 인 정보를 알 수 있었다.

\section{II. 이론적 배경}

\section{1. 교육용 로봇}

교육 분야에서는 로봇을 활용한 다양한 교육활 동들과 보다 효과적인 교육활동 수행을 위한 로 봇 기술 연구가 활발히 진행되고 있다. 교육용 로봇은 개인서비스용 로봇으로 위치 이동 기술, 음성이나 화상 인식 기술, 다양한 콘텐츠 구동 기술 등에 바탕을 두고 학생들의 학습 상황에서 교육대상으로 활용되기도 하고 학습을 보조하거 나 지원하기도 한다. 또한 인터넷과 로봇의 결합 으로 학생과 교사가 멀리 떨어져 있어도 같은 공 간에서 학습하는 것과 같은 효과를 거둘 수 있는 원격교육도 가능하게 되었다.

교육용 로봇이란 교수.학습을 목적으로 교육활 동에서 활용하는 다양한 형태의 로봇을 총칭하는 용어이다. 교육용 로봇에 대하여 객관적으로 합 의를 이룬 분류는 없지만 로봇활용교육과 관련한 선행 연구에서 교육용 로봇에 대한 분류를 살펴 보면 다음과 같다.

강종표(2008)는 교육용 로봇을 새로운 로봇의 개발을 위해서 로봇을 구성하는 '하드웨어의 교 육을 위한 것'과 로봇의 움직임을 제어하기 위한 프로그램인 '소프트웨어를 교육하기 위한 것'으로 구분하였다. 김미량 등(2008)은 교육용 로봇을 크 게 '교구 로봇'과 '교사형 로봇'으로 분류하고, '교 사형 로봇'은 '교사 보조형'과 '동료 교수형'으로 세분화하였다. 송정범 등(2011)도 교육용 로봇을 '교구 로봇'과 '교사 로봇'으로 분류하고 '교구 로 봇'은 '로봇 기술용'과 '통합 교육용'으로, '교사 로봇'은 '교사 보조용'과 '동료 교수용'으로 세분 하였다.

하지만 위와 같은 분류들은 교육용 로봇을 실 제로 분류하는데 있어 몇 가지 어려움이 있다. 예를 들어 강종표의 '하드웨어의 교육을 위한 것' 과 '소프트웨어를 교육하기 위한 것'으로 분류할 경우, 하드웨어와 소프트웨어를 함께 교육할 수 
있는 혼합 형태로 개발된 로봇은 분류하기 어렵 다. 김미량 등(2008)이 분류한 '교구 로봇'과 '교 사형 로봇'의 경우, 하위 개념인 '교사 보조형'이 상위개념인 '교사 또는 교사형 로봇'과 대등한 의 미를 지니고 있기 때문에 의미상 명확하지 않다 는 단점이 있다. 송정범 등(2011)이 분류한 '교구 로봇'과 '교사 로봇'의 분류는 '교구 로봇'과 '교 사 로봇'의 역할을 접목시킨 학생용 텔레프리젠 스(telepresence) 로봇과 같은 형태는 분류할 수 없다는 한계가 있다.

이에 본 연구에서의 로봇활용수업이란 교육용 로봇을 정규교과와 연계하여 교실현장에 직접 적 용한 수업을 의미한다.

\section{2. 수업언어 상호작용유형 분석법}

수업언어 상호작용유형 분석은 1960년대 말 미 네소타 대학의 플랜더즈(Flanders) 교수에 의해 소개된 수업언어 전문 분석법으로, 수업의 주요 변인인 교사와 학생의 언어적 행동에 초점을 맞 추었다는 것과, 수업 중 일어나는 교사와 학생의 언어를 일정한 분류 체계에 따라 체계적으로 기 록하고 분석하는 방향을 제시해 주었다는 점에서 과학적인 수업 분석 도구로 인정받고 있다.

그러나 플랜더즈 분석법은 1960년대 미국의 교 육 상황을 기반으로 하여 고안된 분석 방법으로 우리나라의 수업상황에 그대로 적용하기 힘든 부 분이 있으며, 특히 최근의 변화하고 발전된 수업 형태를 적극 수용하는 데는 한계가 있다.

세부적으로 살펴보면 다음과 같다.

첫째, 당시에 고안된 플랜더즈 분석법은 컴퓨 터 활용을 전제로 설계된 분석 방법이 아니었던 관계로 수업 중 발생하는 다양한 변인을 과학적 으로 기록하고 분석하는 데는 태생적인 한계가 있다.

둘째, 그 구체적인 분석 방법에 있어서도 10 개 의 분류 항목이 명확히 구분되지 않을 뿐만 아니 라 분류 항목을 결정하는 데 있어서도 분류 준칙
이 체계화되지 않아 일선 교사가 수업을 분석하 는 데 있어서 많은 어려움을 호소하고 있다.

셋째, 뿐만 아니라 수업 중 발생하는 교사와 학생의 언어를 단지 10 가지로만 분류함으로 인해 내면적인 수업 정보를 획득하기 어렵다는 단점이 보고되고 있다. 이러한 단점과 사용상의 불편은 일선 교사가 수업 분석을 수행하는 데 걸림돌이 되어 결국 분석의 신뢰성를 떨어뜨리는 상황을 야기하는 단계에 이르게 되었다.

최근 기존 플랜더즈 분석의 아이디어를 적극 수용하면서도 지금까지 약 15 여년 간 교육청, 교 육연수원, 대학원, 예비교사를 대상으로 컴퓨터를 활용한 플랜더즈 분석법을 적용한 사례와 경험을 바탕으로 한층 발전된 분석 방법을 개발하였는데 이 분석법이 $\mathrm{AF}$ (Advanced Flanders) 분석법(변 영계, 김경현, 2005)이다.

$\mathrm{AF}$ 분석법은 기존 플랜더즈 분석과 엄연한 차 이가 있으며 나아가 기존 플랜더즈 분석과는 차 원이 다른 별개의 분석법이라 할 수 있다. $\mathrm{AF}$ 분 석의 주요한 특징은 다음과 같다.

첫째, 플랜더즈 프로그램을 학교 현장에 다년 간 적용한 실증 경험과 최신 연구를 바탕으로 기 존 10 개의 분석 항목을 새롭게 재설정하였다는 점이다.

둘째, 분류 준칙의 실용성을 향상시킨 점이다.

셋째, 수업 언어를 분석하는 데 있어 보다 향 상된(advanced) 질적 정보를 제공한다.

넷째, $\mathrm{AF}$ 분석은 수업언어에서 핵심 요인인 ‘질문'을 상세화하고 분석하는 데 초점을 두고 있 다.

다섯째, 테크놀러지에 기반한 향상된 분석 결 과를 제공한다.

마지막으로 관찰자가 수행한 분석 결과를 웹으 로 전송하여 참여적 수업 정보 데이터베이스를 구축하고 있다.

따라서, 로봇활용수업의 효과성을 검증하기 위 해서는 로봇이 실제로 교사의 수업전문성의 대표 적인 영역인 수업언어를 어떻게 개선하는지에 대 
한 구체적인 데이터가 요구되며, 이에 대한 결과 가 곧 로봇을 학교 교육현장에 도입했을 때의 효 과 여부를 가름하는 중요한 잣대가 될 수 있다.

\section{III. 연구 방법}

본 연구의 목적은 로봇활용수업에서 교사의 수 업언어 사용 유형을 분석하는 것이다. 분석 도 구로 $\mathrm{AF}$ (Advanced Flanders) 분석법을 활용하 였으며 데이터를 실제로 입력하는 과정에서는 ClassReport ver 1.0 컴퓨터 프로그램을 사용하였 다.

\section{1. 연구문제}

$\mathrm{AF}$ 분석을 실시하여 로봇활용수업에서 교사가 사용하는 수업언어의 유형과 분포를 통해 로봇활 용수업이 교사의 수업수행에 미치는 영향을 분석 한다.

\section{2. 연구대상}

본 연구에서는 2011년도에 '로봇활용수업 시범 학교'로 선정된 학교 중 초·중등학교의 로봇활용 집단 총 2개반 24 명(각 1 개반 12 명)을 대상으로 하였다.

참여한 학생의 인적 구성을 분류하면 <표 1> 과 같다.

<표 $1>$ 연구대상 집단의 참여 학생 인적 구성

\begin{tabular}{|c|c|c|c|}
\hline 구분 & 분류 & 학년 & $\begin{array}{llll}\text { 학 생 구 분 합 } & \text { 합계 } \\
\text { 수 } & \text { 계 } & \\
\end{array}$ \\
\hline \multirow{4}{*}{ 성별 } & \multirow{2}{*}{ 남학생 } & 초5 & 6 \\
\hline & & 고1 & 12 \\
\hline & \multirow{2}{*}{ 여학생 } & 초5 & 6 \\
\hline & & 고1 & 0 \\
\hline \multirow{5}{*}{ 성향 } & \multirow{2}{*}{ 외향적 } & 초5 & 4 \\
\hline & & 고1 & 4 \\
\hline & \multirow{2}{*}{ 일반적 } & 초5 & 4 \\
\hline & & 고1 & 4 \\
\hline & 내향적 & 초5 & 4 \\
\hline
\end{tabular}

\begin{tabular}{|c|c|c|c|c|c|}
\hline & & 고1 & 4 & & \\
\hline \multirow{6}{*}{$\begin{array}{l}\text { 학 습 } \\
\text { 수준 }\end{array}$} & \multirow{2}{*}{ 上 } & 초5 & 4 & \multirow{2}{*}{-8} & \multirow{6}{*}{24} \\
\hline & & 고1 & 4 & & \\
\hline & \multirow{2}{*}{ 中 } & 초5 & 4 & \multirow{2}{*}{-8} & \\
\hline & & 고1 & 4 & & \\
\hline & \multirow{2}{*}{ 下 } & 초5 & 4 & \multirow{2}{*}{-8} & \\
\hline & & 고1 & 4 & & \\
\hline \multirow{6}{*}{$\begin{array}{l}\text { 로 봇 } \\
\text { 조 작 } \\
\text { 수준 }\end{array}$} & \multirow{2}{*}{ 上 } & 초5 & 4 & \multirow{2}{*}{8} & \multirow{6}{*}{24} \\
\hline & & 고1 & 4 & & \\
\hline & \multirow{2}{*}{ 中 } & 초5 & 4 & \multirow{2}{*}{-8} & \\
\hline & & 고1 & 4 & & \\
\hline & \multirow{2}{*}{ 下 } & 초5 & 4 & \multirow[t]{2}{*}{8} & \\
\hline & & 고1 & 4 & & \\
\hline
\end{tabular}

\section{Flanders 언어상호작용 분석 도구}

Flanders 수업언어상호작용 분석 도구는 Flanders(1960)에 의해 개발된 '교사의 수업언어 상호작용 분석의 분류’에 기초하여 제작된 도구 를 말한다. 이 분석은 교실수업에서 수업언어와 관련된 체계적인 분류를 제공하는 분석으로, 수 업언어의 분석에 관한 여러 연구(김은주,변지혜, 2009; 김용하, 2008; 박경란, 2005; 김경현, 이재 무, 2004; 나승일, 2003)에서 사용되었다. 데이터 를 실제로 입력하는 과정에서는 ClassReport ver 1.0 컴퓨터 프로그램을 사용하였다.

한편, 본 연구에서는 '질문'을 심층적으로 분석 하기 위해 플랜더즈 분석법에 기초하여 발전된 형태의 $\mathrm{AF}$ (Advanced Flanders) 질문 분석 체계 를 고안하였다. $\mathrm{AF}$ 분석의 질문은 수렴적 질문, 확산적 질문, 수업운영 질문의 세 종류가 있다.

첫째, 수렴적 질문은 사실과 경험에 바탕을 둔 질문으로, 일반적으로 좁은 의미의 질문, 직접적 또는 폐쇄적 질문을 말한다. 이성호(2002)의 제한 형 사고의 폭, Bloom(1956)의 지식·이해·적용 영 역, Moore(2003)의 사실·경험 영역, Blosser(2000) 의 폐쇄형 질문, Richards \& Lockhart(1996)의 수 렴형 질문, Ellis(1991)의 낮은 수준(lower-level)의 질문이 유사한 형태다.

둘째, 확산적 질문은 수렴적 질문과는 대조적 으로, 일반적으로 넓은 의미의 질문, 간접적 또는 
개방적 질문을 말한다. 이성호(2002)의 확장형 사 고의 폭, $\operatorname{Bloom}(1956)$ 의 분석·종합.평가 영역, Moore(2003)의 생산-평가적 영역, Blosser(2000)의 개방형 질문, Richards \& Lockhart(1996)의 확산 형 질문, Ellis(1991)의 고등 수준(higher-level)의 질문이 유사한 형태다.

마지막으로, 수업운영 질문은 '32쪽을 폈나요?', ‘활동을 끝내는 데 시간이 더 필요한가요?' 등과 같이 원활한 수업 진행을 위해 학생의 활동이나 관심을 이동시키거나 관리하기 위한 질문을 말한 다. Blosser(2000)의 관리(managerial) 질문, Richards \& Lockhart(1996)의 절차형 질문이 유 사한 형태다.

한편 수렴적, 확산적 질문은 질문의 수준에 따 라 I·II 수준으로 구분하였다.

수렴 I 수준 질문은 Bloom(1956), Long \& Sato(1983), Brown \& Wragg(1993) 등이 말하는 확인, 명료화, 지식형 질문을 의미하며, 수렴 $\Pi$ 수준 질문은 비교, 분류, 이해와 관련된 닫혀있는 질문을 의미한다.

확산 I 수준 질문은 고차적인 사고를 수반하지 않더라도 답할 수 있는 열려있는 질문으로서 주 로 감각적 감지와 정서표현에 관한 질문이 여기 에 해당된다(예: 본의 풍경을 감상하고 느낀대로 말해보세요). 확산 $\Pi$ 수준 질문은 고차적이고 종 합적인 사고를 요구하는 질문을 말한다. 이와 같 은 분류를 개략적으로 나타나면 아래 <표 2>와 같다.

<표 2> 플랜더즈 분석의 '질문' 상세 분류

\begin{tabular}{|c|c|c|}
\hline \multicolumn{3}{|c|}{$\begin{array}{l}\text { Advanced Flanders 분석의 } \\
\text { '질문' 세부 분류 }\end{array}$} \\
\hline 수렴 I 질문 & \multirow{2}{*}{ 수렴적 } & 기억, 재생, 회상 \\
\hline 수렴 $\Pi$ 질문 & & 비교, 분류, 이해 \\
\hline 확산 $\mathrm{I}$ 질문 & \multirow[b]{2}{*}{ 확산적 } & 감각적 감지, 정서 표현 \\
\hline 확산 П 질문 & & $\begin{array}{c}\text { 고차적 사고 기능 } \\
\text { (문제해결, 비판적 사고, }\end{array}$ \\
\hline
\end{tabular}

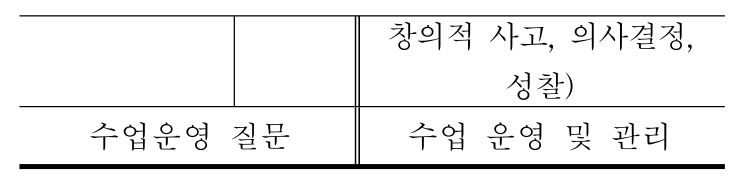

\section{IV. 연구 결과}

본 연구에서는 $\mathrm{AF}$ 분석을 실시하여 로봇활용 수업에서 교사가 사용하는 수업언어의 유형과 분 포를 통해 로봇활용수업이 교사의 수업수행에 미 치는 영향을 분석하였다.

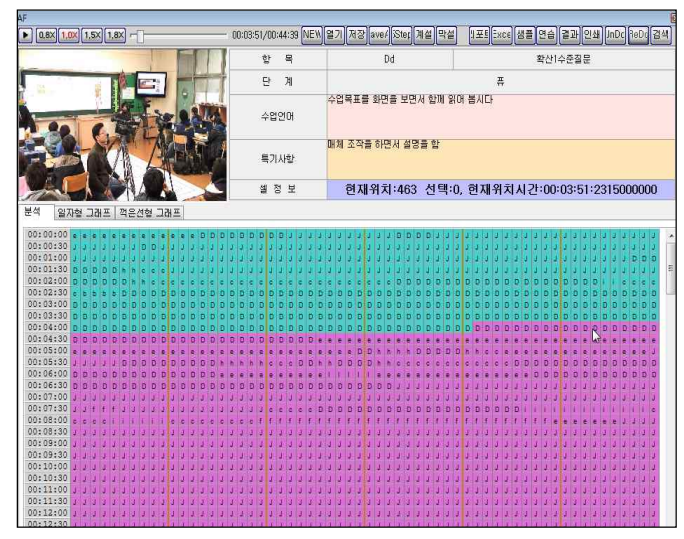

[그림 1] 교사의 수업언어 사용 유형 분석 프 로그램(ClassReport ver 1.0)

\section{1. 수업언어 흐름 분석 결과}

수업언어 흐름은 교사와 학생이 반복적이며 순 환적으로 사용하는 언어 주기(週期)를 의미하며, 여기서는 로봇활용수업과 최적화수업에서 사용한 수업언어의 ‘전체적인 흐름'과 ‘수업 단계별 흐름' 으로 나누어 분석하였다.

먼저, 수업언어의 전체적인 흐름을 분석한 결 과는 <표 $3>$ 과 같다. 표를 보면, 초등학교 로봇 활용수업에서는 '교사의 질문 $\rightarrow$ 학생 답변(반응 적) $\rightarrow$ 학생의 아이디어 수용'이 대표적인 흐름으 로, 중등학교 로봇활용수업에서는 '교사의 질문 $\rightarrow$ 학생 답변(반응적)'이 대표적인 흐름으로 나타 났다. 
<표 3> 수업언어 흐름 전체 결과

\begin{tabular}{l|l|l}
\hline 구분 & 주흐름 & 참고 \\
\hline \hline 초등학교 & $4 \rightarrow 8 \rightarrow 3$ & $\begin{array}{l}3: \text { 학생의 아이디어 수용 } \\
4:\end{array}$ \\
\hline 중등학교 & $4 \rightarrow 8$ & $\begin{array}{l}8: \text { 학생 답변(반응적) } \\
8: \text { 학생 답변(주도적) }\end{array}$ \\
\hline
\end{tabular}

다음으로 수업언어의 단계별 흐름을 분석한 결 과는 아래 <표 $4>$ 와 같다. 표를 보면, 초등학교 로봇활용수업에서는 도입에서 '교사의 질문 $\rightarrow$ 학생 질문(반응적) $\rightarrow$ 학생의 아이디어 수용'으로 나타났고, 전개와 정리에서 '교사의 질문 $\rightarrow$ 학생 질문 $($ 반응적 $) \rightarrow$ 학생의 아이디어 수용 $\rightarrow$ 교사의 질문'로 나타났다. 중등학교 로봇활용수업에서는 도입에서 '교사의 질문 $\rightarrow$ 학생 질문(반응적) $\rightarrow$ 학생의 아이디어 수용 $\rightarrow$ 강의'로 나타났으며, 전 개에서는 '교사의 질문 $\rightarrow$ 학생 답변 $\rightarrow$ 강의 $\rightarrow$ 비언어적 상황'으로, 정리에서는 '교사의 질문 $\rightarrow$ 학생 답변 $\rightarrow$ 강의'로 나타났다.

<표 4> 수업언어 흐름 단계별 결과

\begin{tabular}{l|l|l|l}
\hline 구분 & 도입 & 전개 & 정리 \\
\hline \hline 초등 & $4 \rightarrow 8 \rightarrow$ & $4 \rightarrow 8 \rightarrow$ & $4 \rightarrow 8 \rightarrow$ \\
학교 & $3 \rightarrow 0$ & $3 \rightarrow 4$ & $3 \rightarrow 4$ \\
\hline 중등 & $4 \rightarrow 8 \rightarrow$ & $4 \rightarrow 8 \rightarrow$ & $4 \rightarrow 8 \rightarrow 5$ \\
학교 & $3 \rightarrow 5$ & $5 \rightarrow 0$ & $4 \rightarrow 8$ \\
\hline
\end{tabular}

이상의 분석 결과를 종합하면, 초등학교 로봇 활용수업에서는 '교사의 질문 $\rightarrow$ 학생 답변(반응 적) $\rightarrow$ 학생의 아이디어 수용'이 대표적인 흐름으 로 나타났고, 중등학교 로봇활용수업에서는 '교사 의 질문 $\rightarrow$ 학생 답변(반응적)'이 대표적인 흐름 으로 나타났다.

\section{2. 교사가 사용한 수업언어의 영역별 분포 분석 결과}

교사가 사용한 수업언어의 영역별 분포 분석 결과를 살펴보면 <표 5 >과 같다.
<표 5> 수업언어의 영역별 분포

\begin{tabular}{l|l|l}
\hline \multirow{2}{*}{ 항 목 } & 초등학교 & 중등학교 \\
\cline { 2 - 3 } & 시간비 (\%) & 시간비(\%) \\
\hline \hline 긍정적 발언(1,2,3번) & 9.89 & 28.02 \\
\hline 질문(4번) & 33.15 & 8.6 \\
\hline 강의(5번) & 43.17 & 77.67 \\
\hline 지시(6번) & 4.02 & 0.23 \\
\hline 학생의 발언-반응(8번) & 6.53 & 4.42 \\
\hline 학생의 발언-(9번) & 3.24 & 4.19 \\
\hline 계 & 100 & 100 \\
\hline
\end{tabular}

표에서와 같이 초등학교 로봇활용수업에서는 강의가 $43.17 \%$ 로 가장 많은 비율을 차지하였으 며, 그 다음으로는 질문, 긍정적 발언, 지시 순으 로 나타났다. 중등학교 로봇활용수업에서도 강의 가 $77.67 \%$ 로 가장 많은 비율을 차지하였으며, 그 다음으로 긍정적 발언, 지시, 학생 발언(주도적) 순으로 나타났다. 한편 초등학교 로봇활용수업에 서는 질문과 강의 비율이 크게 차이나지 않는 반 면, 중등학교 로봇활용수업에서는 질문보다 강의 비율이 약 $50 \%$ 높게 나타났다.

이상의 결과를 종합해 보면, 초등학교 로봇활 용수업은 교사가 '강의'를 가장 많이 한 것으로 나타났으며 그 다음으로 '질문'을 많이 한 것으로 나타났다. 또한 중등학교 로봇활용수업은 초등학 교 로봇활용수업에 비해 '강의'와 '긍정적 발언'의 비율이 매우 높았고 ‘지시'는 적게 한 것으로 나 타났다.

\section{3. 비지시적 경향 분석 결과}

비지시비는 교사가 학생에게 얼마나 표현의 자 유를 부여하고 그에 대해 어느 정도 수용적인 반 응을 취했는가를 나타내준다. 일반적으로 비지시 비가 $50 \%$ 이상이면 비지시적인 교사이거나 비지 시적인 경향의 수업이라고 할 수 있다. 
다음의 <표 6>를 살펴보면, 초등학교 로봇활용 수업에서 비지시비는 $47.54 \%$ 로 중등학교 로봇활 용수업에서는 비지시비는 $14.39 \%$ 로 드러났다. 또 한 수정비지시비는 초등학교 로봇활용수업이 $69.92 \%$ 로 나타났고, 중등학교 로봇활용수업은 $95.45 \%$ 로 나타났다. 이에 따라 중등학교 로봇활용수업은 초등학교 로봇활용수업에 비해 비지시적인 경향 성이 낮은 수업으로 드러났다.

$<$ 표 $6>$ 비지시비

\begin{tabular}{l|l|l}
\hline 구 분 & 비지시비 & 수정비지시비 \\
\hline \hline 초등학교 & 47.54 & 69.92 \\
\hline 중등학교 & 14.39 & 95.45 \\
\hline
\end{tabular}

\section{4. 계속적 강의 및 질문비 분석 결과}

계속적 강의비 및 질문비는 교사가 연이어 강 의하거나 질문한 시간 비율을 의미한다. <표 7> 를 살펴보면 초등학교 로봇활용수업이 $47.25 \%$, 중등학교 로봇활용수업이 $62.14 \%$ 로 나타났다. 이 것으로 보아 중등학교 로봇활용수업은 초등학교 로봇활용수업에 비해 교사가 계속적으로 강의하 거나 질문하는 비율이 높았음을 알 수 있다.

<표 7> 계속적 강의 및 질문 비

\begin{tabular}{l|l}
\hline 구 분 & 계속적 강의 및 질문 비 \\
\hline \hline 초등학교 & 47.25 \\
\hline 중등학교 & 62.14 \\
\hline
\end{tabular}

\section{$\mathrm{V}$. 결론 및 제언}

\section{1. 결론}

이상의 연구 결과 다음과 같은 결론을 도출하 였다.

첫째, 초등학교 로봇활용수업에서는 '교사의 질 문 $\rightarrow$ 학생 답변(반응적) $\rightarrow$ 학생의 아이디어 수 용'이, 중등학교에서는 '교사의 질문 $\rightarrow$ 학생 답
변(반응적)'이 대표적인 수업언어 흐름(pattern)으 로 나타났다.

둘째, 초등학교 로봇활용수업에서 교사의 발언 은 '강의'와 '질문' 비율 순으로 높았으며, 중등학 교는 초등학교에 비해 '강의'와 '긍정적 발언' 비 율이 매우 높았고 '지시'의 비율은 낮았다.

셋째, 중등학교 로봇활용수업은 초등학교에 비 해 교사가 계속적으로 강의하거나 질문하는 비율 이 높았고 비지시적인 경향성은 낮았다.

\section{2. 제언}

본 연구 결과와 관련지어 몇 가지 논의할 점과 고려 사항을 제시하면 다음과 같다.

첫째, 초등학교 로봇활용수업에서 교사의 지시 적 발언이 일반적인 수업에 비해(나승일, 2003; 김용하, 2008; 여미란, 2009) 높게 나타난 원인에 대해 논의할 필요가 있다.

이에 대한 원인을 수업 장면에서 관찰한 결과, 초등학교 로봇활용수업은 대부분 모둠 활동으로 이루어진 것으로 나타났다. 학생들은 모둠별로 조립한 로봇을 교실 전면으로 가지고 나와 작동 시켜 보는 활동들을 주로 수행하였는데, 이러한 과정에서 교사가 학생들을 통제하는 장면이 많이 관찰되었다.

예를 들면 교사는 "자리에 가서 앉아.", "누구 야, 이제 그만.", "로봇 만지지마."와 같이 지시적 경향의 발언을 사용하여 학생들을 통제하였다. 한편 본 연구의 결과를 2009년 연구와 연관하여 살펴보면, 2009년 연구에서도 로봇활용수업의 지 시적 발언은 최적화 수업에 비해 높게 나타났다. 이는 로봇활용수업이 최적화수업 교사에 비해 지 시적 발언을 많이 사용한 것을 의미한다.

따라서 초등학교 로봇활용수업에서 나타난 교 사의 지시적 발언은 로봇활용수업의 특징적인 면 으로 해석할 수 있으며, 로봇활용수업은 로봇 기 기로 인해 교사가 학생들의 주의를 집중시켜야 하는 상황이 불가피하게 많이 발생한다고 볼 수 
있다. 하지만 실험·실습이나 노작 위주의 수업에 서도 교사가 학생의 행동을 일정 정도 통제해야 하는 상황이 필연적으로 요구된다는 점을 고려해 볼 때, 로봇활용수업에서 나타난 교사의 지시적 인 언어 사용은 일반적인 수업 상황과 동일하게 설명될 수 있다. 그럼에도 불구하고 교사가 학습 자를 학습에 집중시키고 통제하는 수업 전략의 구안은 로봇활용수업이 학교 현장에 확산 적용되 는 데 있어서 여전히 중요한 과제다.

둘째, 중등학교 로봇활용수업의 비지시비가 초 등학교보다 현저히 낮았다는 점이다.

비지시비는 교사가 수업 중에 어느 정도 긍정 적인 발언을 했는가를 나타내는 수치로, 일반적 으로 비지시비가 높을수록 민주적이고 학생중심 적인 경향의 수업이라 할 수 있다(변영계 외, 2005). 여기서 긍정적인 발언은 학생에 대한 감정 수용, 칭찬 및 격려, 학생의 아이디어 수용을 뜻 하며, 이러한 발언들이 높으면 비지시비가 높게 나타나는 경향이 있다.

한편 수업에서 나타난 비지시비를 해석하기 위 해서는 수정 비지시비에 대한 추가적인 정보가 필요한데, 본 연구에서는 수정 비지시비가 초등 학교와 중등학교에서 각각 $47.25 \%$ 와 $99.92 \%$ 로, 강의와 질문을 제외하면 중등학교 교사가 비지시 적인 언어를 더 많이 사용한 것으로 나타났다. 여기서 수정 비지시비(revised i/d ratio)는 강의 나 질문을 제외한 나머지 발언에서 교사가 어느 정도 비지시적인 언어를 사용하였는가를 나타내 주는 수치다. 여기서 비지시비를 수정 비지시비 와 함께 살펴보는 이유는 강의나 질문은 학생중 심이나 교사중심 어느 편에도 속하지 않는 중립 적인 성격을 갖고 있기 때문이다.

이에 대한 세부적인 원인을 밝히기 위해서는 비지시적인 차이가 교사의 언어적 성향에서 비롯 된 것인지 학습자의 수준과 관련된 것인지에 '학 습자'와 '교사'의 두 측면에서의 추가적인 논의가 필요하다.

먼저, 학습자 측면이다. 전술한 바와 같이 비지
시적인 경향의 발언은 중등학교에서 더욱 많았 다.

이에 대한 원인을 수업 장면에서 찾아보면, 중 등학교에서는 '오, 잘하는데.', '맞아. 그렇게 하는 게 맞아.' 등과 같이 학습자들이 과업을 성공적으 로 수행하였을 때 칭찬하거나 격려하는 발언이 자주 사용되었다. 반면 초등학교는 '그게 아니 지.', '아니. 틀렸어. 왼쪽에다 끼워야해.' 등과 같 이 학생들이 주어진 과제를 해결하기 힘들어하거 나 실패할 경우에 이를 지적하는 발언이 많았다. 이러한 발언의 차이에 대한 원인을 다른 각도에 서 본다면 교사가 학습자의 수준을 적절히 고려 하지 못했다는 점과도 관련된다.

다시 말해, 교사가 제시한 로봇 활동 과제가 초등학교 수준을 초월했거나 지나치게 복잡성을 띠어, 학생이 정해진 시간 내에 해결하기 힘들었 던 것과도 무관하지 않다는 점이다. 이는 수업을 관찰하는 과정에서도 드러났는데, 초등학교 수업 에 참여한 학습자들은 교사가 제시한 과제를 수 행하면서 시간이 부족하다는 말을 반복적으로 했 다든지 로봇을 조립하는 활동 시간이 끝났음에도 불구하고 계속적으로 로봇을 조립했던 학생이 관 찰되었다는 점이 이를 뒷받침한다.

따라서 로봇활용수업에서는 교사가 학습자의 능력을 잘 파악하여 학습자 수준에 맞는 적합한 과제를 제시해야 할 것이 요청된다.

다음으로 교사의 측면이다. 수업 언어는 교사 가 특별하게 주의를 기울이지 않는 이상 평소에 수업에서 사용하는 언어 습관이 일관되게 반영되 어 나타나는 경향이 있다. 때문에 초등학교와 중 등학교에서 비지시적인 언어 사용에 대한 초·중 등학교의 차이는 수업환경, 학생수, 학생수준과 성향과 같은 외부적인 요인보다는 교사의 언어적 성향에 영향을 받았을 가능성이 있다. 따라서 이 에 대한 보다 상세한 결과를 얻기 위해서는 로봇 활용수업에서 로봇매체를 투입하기 전과 후의 교 사의 언어사용에 대한 차이를 비교하는 후속 연 구가 필요하다. 


\section{참고 문헌}

강종표(2008). 초등학교에서의 로봇 교육에 관한 연구, 한국실과교육학회지 16(4), 97 113.

권순범 - 남동수 · 이태욱(2011). STEAM 기반 교 육용 로봇 활용 초등학생 대상 학습 프로그램 개발., 한국컴퓨터정보학회 학술발표논문집.

김경현 · 이재무(2004). 컴퓨터보조 자기장학이 Flanders 주요 수업언어지수 향상에 미치는 효 과, 정보교육학회논문지 8(1), 113 123.

김미량 · 조혜경 · 이석원 · 한정혜 · 한광현 · 김소 미(2008). 창의성 증진을 위한 로봇활용 교육 방안 연구, 한국교육학술정보원 연구보고서(RR 2008-8).

김영실 - 이종향 - 현은자 - 박현경(2011). 지능형 로봇을 활용한 동시활동이 4 세 유아의 음운인 식과 단어재인에 미치는 효과, 열린유아교육연 구 16(1), 389 409.

김용하(2008). 플랜더즈의 수업분석 방법에 따른 지체부자유학교 초등부 교사의 언어상호작용 분석, 대구대학교 석사학위논문.

김은주·변지혜(2009). 플랜더즈 언어상호작용분 석법에 의한 유치원 수업분석, 한국유아교육보 육행정연구 13(2), 97 121.

나승일(2003). 플랜더즈 언어상호작용 분석법을 이용한 농고 교육실습생의 연구수업 분석, 농 업교육과 인적자원개발 35(2), 25 40.

박경란(2005). PDA환경 기반 웹용 플랜더즈 언어 상호작용 시스템 설계 및 구현, 이화여자대학 교 교육대학원 석사학위논문.

박응식 - 문성환(2009). 초등학생의 논리적 사고력 신장을 위한 로봇 교육 프로그램 개발 및 적 용, 한국실과교육학회지 22(1), 175 198.

박정호 · 김철(2011). 초등학교에서 로봇활용 미술 수업이 창의성 신장에 미치는 효과, 정보교육 학회논문지 15(2), 277 285.

박정호· 조혜경(2011). 초등학교 정규교과에서 로 봇활용수업 적용 사례 연구, 한국컴퓨터정보학 회 논문지 16(8), 67 76.

변영계·김경현(2005). 수업장학과 수업분석, 서 울:학지사

송정범 · 권오성 · 고병오 · 양권우 · 신수범(2011). 초등학교에서 로봇활용 미술수업이 창의성 신 장에 미치는 효과, 한국컴퓨터교육학회 14(1), 35 43.
신나민 - 김상아(2007). 로봇과 학습의 관계 맺기: 초·중·고등학생의 관점에서, 교육정보미디어연 구 13(3), 79 89.

여미란(2009). Flanders 언어 상호작용 분석법을 이용한 유치원과 초등학교의 수업형태분석 : 이야기나누기를 중심으로, 부산대학교 석사학 위논문.

유구종 - 김민경 - 이정순(2011). 지능형로봇을 활 용한 유아교육기관 선택활동프로그램 구성 및 효과, 열린유아교육연구 16(4), 493 520.

이경희 · 류영선 · 문성환(2010). 로봇 교육활동을 통한 초등학생의 주의력 향상 모색, 한국실과 교육학회지 23(1), 185 204.

이성호(2002). 교수방법의 탐구, 서울: 양서원.

이영준 · 김경 - 유헌창 - 임웅 · 계보경(2007). 로봇 의 교육적 활용방안 및 적정 기능 연구, 한국 교육학술정보원 연구보고서.

한정혜 - 김동호(2006). 교사 보조 로봇의 교육적 활용, 정보교육학회논문지 10(1), 849 856.

Bloom, B. S.(1956). Taxonomy of Educational Objectives, Handbook I: Cognitive Domain, NY: David McKay Co.

Brown, G., \& Wragg, E. C.(1993). Questioning, NY: Routledge.

Culp, K. M., Honey, M., \& Mandinach, E. (2004). A retrospective on twenty years of education technology policy, U.S. Department of Education, Office of Educational Technology.

Flanders, N. A.(1960). Teacher influence, pupil attitudes and achievement, Minneapolis: University of Minnesota.

Long, M. H., \& Sato, C. J.(1983). Classroom foreign talk discourse: Forms and functions of teacher's question, Classroom oriented research in second language acquisition. Mass.: Newbury House Publishers.

Moore, K. D.(2003). Classroom teaching skills, NY: McGraw-Hill.

- 논문접수일 : 2012년 08월 28일

- 심사완료일 : 1차 - 2012년 09월 13일

- 게재확정일 : 2012년 09월 14일 